\title{
High School Student Rationales for Studying Advanced Science: Analysis of Their Psychological and Cultural Capitals
}

\author{
Mei-Shiu Chiu \\ National Chengchi University, Taiwan \\ Email: chium@nccu.edu.tw; meishiuchiu@gmail.com
}

\begin{abstract}
This study aimed to identify the psychological capitals (PsyCaps) and cultural capitals (CulCaps) of high school students who chose to study advanced science. Semi-structured interviews were conducted with 47 high school students in Taiwan to obtain the life experiences and rationales that motivated them to study science. Qualitative analysis of the science student data showed that PsyCaps and CulCaps tended to function in pairs and follow a PsyCap-CulCap configuration: interest (optimism)-materials, confidence (self-efficacy)-scores, resilience (control)-strategies, valueauthorities, and hope (goal)-designs. The configuration was operated by the mechanism: ideal form of professional self abstracted from domain and social comparisons. Teachers can invite students to reflect on the PsyCap-CulCap configuration to guide them toward appropriate decisions on pursuing a career in science.
\end{abstract}

Keywords: Cultural capital; psychological capital; science learning; secondary education

\section{Introduction}

Choosing to study advanced science in high school implies an intention to pursue a higher education and career in science (Van Houtte, Vanderwegen, \& Vermeersch, 2014). The high-stakes decision of whether to enter the sciences ideally involves informed capital use by students. Students in science choices are similar to entrepreneurs in business ventures involving the use of psychological capitals (PsyCaps) and cultural capitals (CulCaps) (Baron, Franklin, \& Hmieleski, 2013; Maltese \& Tai, 2010). Adopting a capital perspective toward student science choice with reference to research on PsyCaps and CulCaps may aid in configuring a comprehensive understanding of student decision-making processes, frames of reference, interpretations of their world, life styles, and attitudes (Attarian, 1978). The identified PsyCaps and CulCaps can serve as effective educational measures to guide students considering studying or seeking a career in science (Demerouti, Van Eeuwijk, Snelder, \& Wild, 2011). The objectives of this study, therefore, are to:

Identify PsyCaps and CulCaps that high school students use when they choose to study advanced sciences.

Use a qualitative methodology to integrate diverse psychological concepts (i.e., PsyCaps) with sociocultural ones (i.e., CulCaps).

\subsection{Defining Capitals in Student Science Choices}

Studies on science education have identified or predetermined a number of factors that influence student science choices. For example, Maltese and Tai's qualitative study (2010) indicated that the sources of student interest in science include self (e.g., interest and curiosity) (45\%), school or informal education activities (e.g., science camp and competitions) (40\%), and family (e.g., parent encouragement and pressure) (15\%). Cerinsek, Hribar, Glodez, and Dolinsek's (2013) quantitative study predetermined factors influencing student science choices such as career priorities (e.g., interest, identity, and values), key persons (e.g., teachers and parents), school experiences (comparison in performance across domains and classroom experiences), and outside school experiences (e.g., museums, computer games, and books). The factors are consistent with the components of PsyCaps in research on business or psychology, and those of CulCaps in sociology or the sociology of education, but are not structured into meaningful 
configuration if not referring to existing system-based theories (to be addressed in the section of Theories Linking PsyCaps with CulCaps).

The preceding literature on factors in student science choices suggests that in this study capitals can be defined as factors in studying advanced science, which include psychological (e.g., self and interest) and cultural (e.g., education and family) aspects or capitals. PsyCaps can be defined as affective resources managed by individuals that can promote positive developments of choices or engagement in science study or career (Siu, Bakker, \& Jiang, 2014). CulCaps may include significant artifact and human resources that interact with students in the process of studying science (Archer et al., 2012; Bourdieu, 1973).

\subsection{Components of PsyCaps}

Various psychological theories have indicated that PsyCaps may relate to career choices and ventures. In business management research, PsyCap is typically defined as comprising four constructs: self-efficacy, optimism, hope, and resilience (Luthans, Avey, Avolio, Norman, \& Combs, 2006). Educational researchers typically use motivations as PsyCaps for positive learning processes or outcomes and may include constructs such as confidence, control, interest, value, and goals in learning or teaching (Pintrich, 2003). Self-determination theory suggests that intrinsic motivation is more desirable for learning behavior than extrinsic or no motivation is (Ryan \& Deci, 2000).

Studies examining some specific PsyCaps for studying science are relatively common in the science education literature. Interest and confidence are the most influential PsyCaps in choosing to study science, according to students (Venville, Rennie, Hanbury, \& Longnecker, 2013). Biology interest predicts school student biology career orientations (Uitto, 2014). Confidence in mathematics tends to be the strongest predictor of mathematics achievement (Chen, 2014). The plentiful related literature may justify using a quantitative methodology to examine well-researched PsyCaps (e.g., interest and confidence).

\subsection{Components of CulCaps}

CulCaps have a theoretical root in sociology or the sociology of education. Education plays a major conservative role in cultural transmission and reproduction, saliently operated by teachers, parents, and cultural facilities (e.g., museums), which are example components of CulCaps (Bourdieu, 1973). Thus, CulCaps may include artifact or human aspects of value and power situated in a context that can influence student decisions to study science (Gazley et al., 2014). The two aspects may appear distinct but in fact may be difficult to separate because artifacts are human creations and may include both tangible materials and intangible designs. For example, content, procedures, and learning and teaching materials for a specific domain of knowledge (e.g., physics) are the creations of humans (typically professionals) in the field (e.g., physicists, engineers, and related professionals). Researchers tend to deal with the following three major types of CulCaps for students studying advanced science.

Parents and Parenting Activities. Students pursuing an education or career in science appear to highly relate to parental provisions of science activities starting from early childhood (Archer et al., 2012). Unconditional support, encouragement, and persuasion from parents provide formative science experiences for future science students (Maltese \& Tai, 2010). Packard, Babineau, and Machado (2012) qualitatively demonstrated that Latina mothers' vocational values (e.g., job security, stable income, and a safe future in higher education) appear to influence their daughters to choose nurse-preparation programs in high school.

Teachers and Teaching Activities. Student science interest may be influenced by teacher characteristics, comments, and teaching activities such as projects, experiments, and demonstrations (Maltese \& Tai, 2010). Student participation in science activities (e.g., experiments, collecting things from nature, and reading science books), however, indirectly predict science choices, though directly predict science PsyCaps (e.g., interest, confidence, and value) (Simpkins, Davis-Kean, \& Eccles, 2006). Student science choices may negotiate with high school curriculum and college entrance examination designs (Ametller \& Ryder, 2015).

Domains and Job/Career Activities. Student rationales for choosing to study science may include testing their interest in sciences, changing from another domain, and building a path toward an ideal 
job-related reputation or status (Gazley et al., 2014). Students may pursue a career in science if they interpret it as being formative (special and beneficial), performative (practical), consequent (influential), or potential (expanding) (Hsu, Roth, Marshall, \& Guenette, 2009).

\subsection{Theories Linking PsyCaps with CulCaps}

Researchers have linked PsyCaps with CulCaps in two regards: systems and mechanisms. The system indicates the components of PsyCaps and CulCaps and how the componentsi are structured into diagrams; the diagrams explain relationships among the components. The mechanism indicates operations to produce effects in the system. For example, the circle in the center of Figure 1 indicates the mechanism, while the other parts in Figure 1 are the system. Studies indicating system and mechanism regards are separately reviewed as follows.

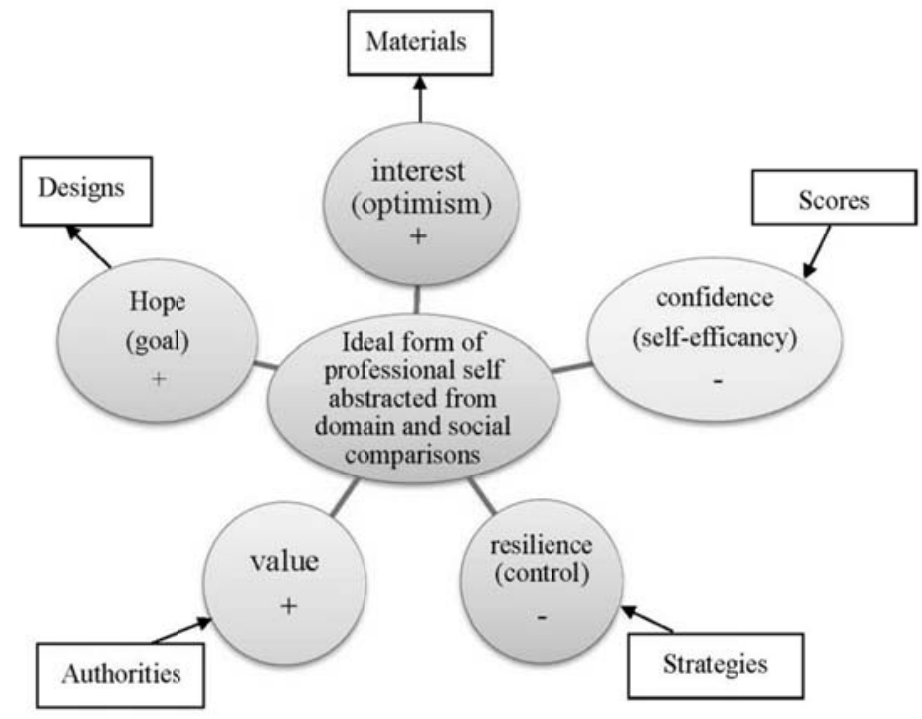

Figure 1. The configuration of PsyCaps and CulCaps for studying advanced science. "+" refers to positive tones and "-" to negative tones.

Systems. Researchers have posited systems or models suggesting that career-related choices may relate to PsyCaps, which can be traced to or interwoven with some related CulCaps (Regan \& DeWitt, 2015, p. 66). For example, Ainley and Ainley (2011) posited a system that conceptualizes embedded science interest (PsyCap) as an outcome influenced by socioeconomic status, science knowledge (CulCap), personal value of science, enjoyment of science, and interest in learning science. Science students are attracted to the subject because it includes tangible, logical, and strict procerdures (CulCap), and because they enjoy processing science, thinking problems, and finding solutions (P'syCap) (Holmegaard, Madsen, \& Ulriksen, 2014). The expectancy-value theory indicates that achievement-related choices are determined by expectation of success and subject task values (PsyCap), which may be influenced by diverse precedent factors such as goals, affective memories, stereotypes, interpretation, culture (CulCap), societal attitudes, and achievement (Bøe, Henriksen, Lyons, \& Schreiner, 2011; Wigfield \& Eccles, 2000). These systems appear to combine parts of PsyCaps or CulCaps and may suggest a need to differentiate and integrate complete PsyCaps and CulCaps into a system based on empirical datia.

Mechanisms. Likely mechanisms for science students to make sound decisions about studying advanced science may include domain and social comparisons. Student preferences toward different domains may vary (Paik \& Shim, 2013). Students are likely to compare their achievements in different domains and thus form different confidence beliefs for each domain (Marsh \& Hau, 2004). Through social comparisons (e.g., with peers), science students may form perceptions of themselves as possessing a higher ability in science than some others in a society and thus enter advanced sicience study and seek a science career (Chiu, 2012). Most past studies have used a quantitative methodology to examine the 
mechanisms of the domain and social comparisons, which may be further elucidated using a qualitative methodology.

\subsection{Research Questions}

Based on the review of the literature, this study attempts to answer a major research question:

What are high school students' rationales for choosing to study advanced science?

The major research question is divided into two parts.

1. What are critical PsyCaps and CulCaps, which form a system, in the rationales?

2. What is the mechanism through which the system operates?

\section{$2 \quad$ Method}

\subsection{Educational Designs for High School Students in Taiwan}

Senior high school in Taiwan comprises Grades 10-12, with students typically aged 16-18 years. A national curriculum implemented in 2010 set Grade 10 as the final year when all students take similar courses (Chiu, 2016). Beginning in Grade 11, students select one of the three course packages to study. Package 1 focuses on the humanities and social sciences (i.e., history, geography, and citizenship), Package 2 on physical sciences (i.e., advanced mathematics, physics, and chemistry), and Package 3 on natural sciences (i.e., advanced mathematics, physics, chemistry, and biology). Students who choose Package 1 are generally referred to as "humanities students," and those who select Package 2 or 3 are termed "science students"; these terms are used throughout this paper. All students must study Chinese and English in Grades 10-12, though humanities students study only basic mathematics in Grades 11 and 12 (Table 1 ).

Table 1. Design of academic domains in the national high school curriculum of 2010, Taiwan

\begin{tabular}{c|c|c|c|c|c|c|c}
\hline & Domains & Mathematics & $\begin{array}{c}\text { Physics and } \\
\text { chemistry }\end{array}$ & Biology & $\begin{array}{c}\text { Earth } \\
\text { science }\end{array}$ & $\begin{array}{c}\text { Chinese } \\
\text { and } \\
\text { English }\end{array}$ & $\begin{array}{c}\text { History, geography } \\
\text { and citizenship }\end{array}$ \\
\hline $\begin{array}{c}\text { Grade } \\
10\end{array}$ & All students & basic & basic & basic & basic & same & basic \\
\hline $\begin{array}{c}\text { Grades } \\
\text { 11-12 }\end{array}$ & $\begin{array}{c}\text { Package 1 (humanity) } \\
\text { students }\end{array}$ & basic & basic & basic & basic & same & advanced \\
\hline & $\begin{array}{c}\text { Package } 3 \text { (nhysical } \\
\text { science) students }\end{array}$ & advanced & advanced & no & (optional) & same & basic \\
\hline
\end{tabular}

Two college entrance examinations are designed for students aiming to go to higher education. At the end of the first semester of Grade 12 (two semesters in an academic year in Taiwan), almost all high school students take the first examination, which tests student basic abilities on five contents: Chinese, English, mathematics, sciences (physics, chemistry, and biology), and social sciences (history, geography, and citizenship). In other words, the first examination includes all of the 10 academic domains in the curriculum. Most students use their first examination results to go to university by applications. If students decide not to go to university using the first examination results, at the end of Grade 12 , they can choose to take the second examination, in which all students take Chinese and English tests, but can choose to take humanity mathematics, history, geography, and citizenship tests (for humanity students) or/and to take advanced mathematics, physics, chemistry, and biology tests (for science students).

The school curriculum and college entrance examination designs in Taiwan appear to allow for limited student choices. The process of student science choices in the educational designs of Taiwan may be 
different from that of countries where students can have multiple courses and examinations to choose from (Ametller \& Ryder, 2015; Cleaves, 2005).

\subsection{Sample}

The research participants were 47 science students (27 girls and 20 boys; forty-five 11 th and two 12 th graders) from Northern, Central, Southern, and Eastern Taiwan. Most of the students were in their second year of senior high school (i.e., Grade 11), and thus had chosen their course packages (Table 1) and should have possessed substantial knowledge about all academic domains in the school system.

\subsection{Data Collection and Tools}

The research participants were interviewed individually in Mandarin Chinese by trained interviewers. The interviews lasted for approximately 1 hour and were audio-recorded. The interviewee's ideas were elicited by the following interview questions as the research tools.

1. Which course package do you choose: Package 1 (the humanities and social sciences), Package 2 (the physical sciences), or Package 3 (the natural sciences)?

2. What are your rationales for choosing this course package?

3. When do you find that you are suited to this course package? Please share all your life experiences relating to this. What are your concerns during these life experiences? Do any people, events, or materials significantly influence your choice?

4. What are your thoughts about the interview?

Interview Question 4 allowed the interviewees to pose questions and the interviewers answered questions in order to reduce power asymmetry and increase dialogical equality in the intervieweeinterviewer relationship (Kvale, 2006, 2008).

\subsection{Data Analysis}

All the interviews were transcribed. Research Question 1 for identifying the configuration of PsyCaps and CulCaps used in student science choices was answered using word data from student responses to the qualitative mode of the basic and follow-up questions in the interview. The data were examined using the methodologies of general qualitative data analysis (Kahlke, 2014; Miles \& Huberman, 1994) with elements of narrative analysis (Holmegaard, Ulriksen, \& Madsen, 2015; Labov, 2006), phenomenography (Marton, 1981), and grounded theory (Charmaz, 2000; Corbin \& Strauss, 2007; Strauss \& Corbin, 1990). The general qualitative methodology was used to design the analysis procedure, which included open coding, story configuration, constant comparison, and theoretical saturation. The open coding was partially conducted using Atlas.ti Version 6.0.15 (Atlas.ti GmbH, Berlin, Germany). The open coding provided a rough initial overview of all the student stories. By narrative analysis, the student story with the most vivid and thorough descriptions was analyzed in-depth and established as the base story. The use of base studies facilitated the development of an initial coherent, meaningful system and the identification of the mechanism in this study and in related studies (Ametller \& Ryder, 2015). By phenomenography and grounded theory, qualitative variations in the students' stories were constantly compared, gradually added into the base story, and formed distinct categories until a complete configuration (e.g., Figure 1) had been formed and nothing could be added to enrich the configuration further (i.e., status of theoretical saturation).

\section{$3 \quad$ Results}

\subsection{System of PsyCaps and CulCaps for Studying Advanced Science}

The final configuration of science students' capitals for studying advanced science (Figure 1) was developed based on the qualitative analysis of science students' stories. The responses by a Grade 11 science student (Girl, ID = s19) formed the base story and her statements are extensively quoted in this paper. The configuration comprised the following five PsyCap-CulCap pairs: interest (optimism)- 
materials, confidence (self-efficacy)-scores, resilience (control)-strategies, value-authorities, and hope (goal)-designs. The order is based approximately on the sequence of responses provided by the students to the major interview questions about rationales for studying advanced science.

Interest (Optimism) and Materials. The students typically first discussed their personal interest in science when responding to the interview questions about their rationales for studying advanced science (Course Packages 2 and 3) in Grade 11. After the interviewers asked "Why did you choose the [physical or natural] sciences course package?" most of the students responded by describing their interest and preferences with a positive tone. Two such responses were as follows:

1. I am very interested in natural science. (Girl, Grade 11, Package 3, Eastern Taiwan, ID = s24)

2. I don’t like geography, history, or citizenship. (Girl, Grade 11, Package 3, Northern Taiwan, ID $=\mathrm{s} 19)$

3. Educational materials served as the major CulCaps for students to find a personal interest in an academic domain.

4. When I learned chemistry and biology in Grade 10, I felt interested. (Girl, Grade 11, Package 3, Eastern Taiwan, ID = s24)

5. I like to see photos from foreign countries in geography textbooks. (Boy, Grade 11, Package 2, Southern Taiwan, ID = s51)

The students appeared to have used interests to make a first, intuitive, and optimistic assessment of the unique essence of the domains, as reflected by the cultural artifacts of educational materials. Small future creators (i.e., science students) appear to have actively responded to big creators' creations (educational materials as cultural heritage) produced by past science professionals (Leu \& Chiu, 2015). The active response of personal interest to science materials (cultural artifacts) appears to have provided the students with optimism regarding their future development of science-related skills.

Confidence (Self-Efficacy) and Scores. Confidence or self-efficacy may have been the second most popular rationale for the students to study advanced science. After students stated that they choose to study advanced science because of personal interest, the interviewers asked follow-up questions such as "Why are you so interested in science?" The students' responses to the follow-up question were normally related to concerns about test scores.

I cannot get good results in geography, history, and citizenship. I spend much time on these subjects but the results are still not ideal. (Girl, Grade 11, Package 3, Northern Taiwan, ID = s19)

The sudden change from interest (with positive tones) to scores (with negative tones) may be surprising because the follow-up question is intended to find reasons (positive CulCaps) behind the interest. Scores appeared to be part of the reason for interest and a negative concern. Confidence (PsyCap) was not clearly mentioned with scores (CulCap) in the interviews. In the literature, scores and confidence appear to be closely related. Scores are a human artifact or CulCap, that can lead to student senses of ability or achievement, known as confidence and academic self-concept (Chiu, 2012) for domains or self-efficacy for specific tasks (Bandura, 2004). A note to make is that interest (PsyCap) was clearly mentioned before educational materials (CulCap) in the interviews.

Resilience (Control) and Strategies. Some students proposed their strategies for learning diverse domains as rationales for studying advanced science.

I choose Package 2 [physical sciences] because biology needs memorization, though chemistry also needs memorization. (Boy, Grade 11, Package 2, Southern Taiwan, ID = s51)

The students experimented with the diverse learning strategies available to them, aiming to find effective means of controlling their learning process and outcomes. Striving to use multiple strategies creatively and intensively indicates resilience.

I use "problem sea" [practicing many problems] as a strategy to learn mathematics, and the strategy works. I used all strategies such as preview, "problem sea," overview, etc. for history but still failed. (Girl, Grade 11, Package 3, Northern Taiwan, ID = s19)

The resilience (control)-strategies pair appeared to be mentioned in a negative tone by science students especially when they stated their strategies for studying social sciences. The science students tended to view the social sciences as problems that were difficult to solve or control by using available strategies. Strategies (CulCap) were expressed before resilience (control) (PsyCap) in the interview, perhaps because of the negative experiences of learning social sciences.

Value and Authorities. Values were the third PsyCap, appearing after expectations conveyed by authorities (or influential people and powerful organizations) in the science student responses about 
their life experiences. The first and most crucial authority for children and adolescents may be parents. Some students were highly influenced by their parents in choosing to study advanced science, particularly those who selected Package 3; some science-related jobs tend to have high vocational reputations in Taiwanese society.

My dad wants me to become a doctor... because he wants me to follow his career path. My father is a medical doctor. (Boy, Grade 11, Package 3, Northern Taiwan, ID = s41)

However, not all students were able or willing to yield to their parents' wishes. They followed their own preferences and cherry-picked values from other authorities to support their own choices.

Student: I choose Course Package 2 [physical sciences] because I'm not good at either the humanities or biology. My parents told me that I was not good at sciences. I told them that I was not good at the humanities either. All the cram school teachers said that it was better to choose a science course package.

Interviewer: What did they say?

Student: They said that choosing science was better because of the curriculum change and because there would be more science departments in universities. (Girl, Grade 11, Package 2, Southern Taiwan, ID = s50)

The students sought support from authorities, particularly when their choice conflicted with that of their parents. The students appeared to assign less weight to reasons for studying advanced science provided by the nonparent authorities.

Hope (Goal) and Designs. Most secondary students hope to advance to tertiary education and educational designs appear to be game rules that determine who can succeed. Students critically examine and exploit existing educational designs to achieve their academic and career goals.

Student: My older sister said that "if you do not know what to do, you can choose Package 3, in which you can learn more and make another choice [later]." Choose Package 3 and you'll have more choices [because Package 3 includes all advanced science courses, the university entrance examination includes all the 10 academic domains, and there are more science departments in universities].

Interviewer: But Package 1 also includes many domains.

Student: But Package 1 is relatively shallow [in advanced science, only including basic science courses. Science is difficult and I need more advanced science courses. Package 3 is relatively shallow in the humanities but I can learn the humanities on my own relatively]. (Boy, Grade 11, Package 3, Northern Taiwan, ID = s41)

At first, I chose Course Package 2 [physical sciences]. It impressed me that when I was in Grade 10, my biology teacher told me that I got perfect marks, which was the only case of that in his teaching career. I feel I'm good at biology. So, at last, I chose Course Package 3 [natural sciences]. (Girl, Grade 11, Package 3, Central Taiwan, ID = s04)

The two foregoing excerpts indicate how examination and teaching designs (or teacher behavior) may influence students to decide to study advanced science. In other words, studying advanced science may simply be a form of negotiation between personal goals and external goal structures revealed by educational designs.

The literature indicates that goal structures of teaching may influence students to adopt mastery or performance goals (O'Keefe, Ben-Eliyahu, \& Linnenbrink-Garcia, 2013). The current study further indicated that educational designs do not have an arbitrary role in learning but rather may interact with student aptitudes for maximizing positive outcomes. In this sense, the hope (goal)-designs pair appears to show that students' hope (goal) (PsyCap) is more crucial than educational designs (CulCap).

\subsection{Mechanisms}

The aforementioned qualitative results reveal the configuration of five PsyCap-CulCap pairs (Figure 1). Three mechanisms emerged from the configuration: (1) the abstracted ideal form of professional self, (2) domain comparisons (i.e., comparisons between domains of knowledge), and (3) social comparison (particularly comparison with peers).

The Abstracted Ideal Form of Professional Self. The central mechanism for studying advanced science appears to be students' ultimate ideal form of professional self (Adler, 2009, p. 105) abstracted by exercising related PsyCaps and CulCaps. The abstracted ideal form of professional self is justified by 
two phenomena. First, the capitals sometimes are interwoven and indistinguishable, as shown by the following quotation, in which interest appears to be rooted in strategies.

I don't like to memorize social science domain content. (Boy, Grade 11, Package 2, Southern Taiwan, ID = s51)

Second, CulCaps sometimes may be completely internalized by students. The passive CulCaps appeared to have been gradually masked before becoming an active, self-determined choice to study advanced science. The ideal form of professional self appears to be vague and abstracted from interactions between the PsyCaps and CulCaps.

I chose natural science because I hope to become a medical doctor. My parents are both medical doctors. They have always been my role models. They said that being a doctor would be better. I think the most important thing is to take care of the people around me. A family needs someone who understands medicine so they don't panic about health problems. I can save people around me. That is my own thought. (Girl, Grade 11, Package 3, Northern Taiwan, ID = s19).

The abstracted ideal form of professional self-appeared to become the main determiner guiding students to study advanced science. The main determiner, however, appeared to be vague, unstable, and uncertain because domain and social comparisons involving multiple capitals continued to affect the study and school lives of the students.

Domain Comparison. Students make multiple comparisons among domains of knowledge during decision making. For example, after the interviewer asked "Why did you choose Package 2?" a student responded:

Because I am not good at social science. I am better at natural science. [Also,] I am not interested in social sciences. (Girl, Grade 11, Package 2, Eastern Taiwan, ID = s28)

Social Comparison. Social comparison is the third mechanism. The typical targets for comparisons were peers.

I really liked my Grade 10 mathematics teacher. He lets us use our brains. Sometimes he showed us some special toys, like a chain. It was very interesting. Some classmates didn't like it. They like to solve problems and go to cram school; they study the social science course package. (Girl, Grade 11, Package 3, Northern Taiwan, ID = s19)

The science students appeared to strengthen their self-understanding of their science skills by comparing their performances with that of peers.

\section{Discussion}

\subsection{Capital System}

This study used a qualitative methodology to identify five PsyCap-CulCap pairs exercised by students when deciding whether to study advanced science. The pairs were interest (optimism)-materials, confidence (self-efficacy)-scores, resilience (control)-strategies, value-authorities and hope (goal)-designs, as presented in Figure 1. In the interviews, the students tended to state PsyCaps before CulCaps when discussing the interest (optimism)-materials and hope (goal)-designs pairs and to state CulCaps before PsyCaps when discussing the other pairs. The students tended to speak with positive tones when discussing the interest (optimism)-materials, value-authorities, and hope (goal)-designs pairs, and with negative tones when discussing the confidence (self-efficacy)-scores and resilience (control)-strategies pairs. The PsyCap-CulCap configuration extends the theory of PsyCap in management to motivational constructs (e.g., value) in education with different valances (e.g., confidence in a negative direction) linking to slightly different CulCaps such as resilience (control)-strategies rather than resilienceadversity, as indicated by Chen and Lim (2012).

The results suggest opportunities and challenges students face in their science choices. The opportunities occur in the positive aspect. Interest plays the most important role in student science choices as interest is mentioned firstly and before its CulCap (learning materials) in the interview. Frequent access to learning materials starting from early years may be an effective measure to find student's interest in a domain. Interest and hope are positive PsyCaps guiding students into science choices, with interest being more subject orientation and hope more career orientation (Ametller \& Ryder, 2015). The value-authorities pair comprises both opportunities and challenges. Values tend to be 
an internalized positive identity, negotiating with authorities in the culture. Although parents serve as the most significant authority in some students' science choices, some other students find alternative authorities (e.g., teachers) to justify their own choices. Educators need to highlight the challenge for students to keep an honest identity in negotiating self with parent choices. The challenges occur largely in the negative aspects. Scores and strategies are dominating CulCaps when students confront difficulties with their PsyCaps (confidence and resilience) being hidden and reduced under the undesirable situation. Educators need to be sensitive to student voices about scores and strategies, which are signs of learning difficulties with hidden PsyCaps in negative directions.

Choosing to study advanced science involves both individual-psychological and sociocultural processes (Holmegaard, Ulriksen, \& Madsen, 2014). Students must negotiate between multiple PsyCaps and CulCaps. According to intuition or self-determination theory (Deci \& Ryan, 2000), PsyCaps should provide more insight regarding choosing whether to study advanced science than should CulCaps. However, this study found that CulCaps appeared to be more influential than PsyCaps, except for the interest (optimism)-material and hope (goal)-designs pairs. However, although CulCaps dominate, interest was still the first concern of the students. The results may expand research on the vital role of interest in science education (e.g., Maltese \& Tai, 2010).

Interest is optimistically perceived by student intuition as the most crucial capital in studying advanced science, but a complex system appears to lie behind interest. Teachers must help students look deeper at their interest. How do students actually define "interest"? Is student interest actually combined with contextualized confidence (self-efficacy), resilience (control), value, or hope (goal)? The present findings provide a configuration (Figure 1) as a workable standard of operation for teachers to help students discover and examine the capitals relating to their choices to study advanced science.

\subsection{Mechanism: Ideal Form of Professional Self Abstracted from Domain and Social Comparisons}

Qualitative results revealed that the abstracted self is the central mechanism through which the students chose to study science. The most influential PsyCap, interest, can be traced to students' ideal form of professional self. The culturally constructed concept of interest prepares and equips students with optimism for overcoming difficulties and challenges in their long, possibly tedious journey to the ideal form of professional self (Adler, 2009, p. 105). In other words, students studying advanced science represent their self-preparation and self-equipment toward their ideal forms of professional selves manifested by the five PsyCap-CulCap pairs (Figure 1).

Domain and social comparisons follow the aforementioned suggestion that highly influential CulCaps surround the abstracted ideal form of professional self. Students emphasize PsyCaps (particularly interest [optimism] and slightly hope [goal]) as the major basis for choosing to study advanced science. CulCaps, however, may lead students to become business investors or social reproducers because of their tendency to seek social desirability, which may prevent students from being free learners. The mechanism of developing ideal selves through domain and social comparisons appears to trigger this non-free learning. If freedom to learn is an aim, educators may need to raise student awareness about the dynamic self-abstracted from relevant capitals, using domain and social comparisons.

The abstracted ideal form of professional self may or may not be appropriate for student decisions on pursuing a career in science (Adler, 1989, p. 517). Educators may need to judge the appropriateness of a student choosing to study science by understanding how the student's PsyCap-CulCap configuration works. Perhaps the first salient sign of an inappropriate professional self is that students lack interest in science but choose to study advanced science. Educators may need to view interest (optimism) in science as a necessary student capital to overcome difficulties, succeed in studying science, and pursue a career in science. Educators may need to help students convince themselves through reflection on the capitals identified in this study before students decide to study and invest time and effort in advanced science. Some students may be passively constrained by the capitals (or conditions). Some other students may interact with and actively exercise creative power over the PsyCap-CulCap configuration (Figure 1), which is a sign of strong professional self after domain and social comparison and can avoid regret after choosing to study advanced science. 


\section{Conclusion}

Interview and later qualitative data analysis find the PsyCaps and CulCaps that high school science students in Taiwan use when they choose to study advanced science. The major findings include:

1. High school students use five pairs of PsyCap-CulCap as their major rationales for choosing to study advanced science: interest (optimism)-materials, confidence (self-efficacy)-scores, resilience (control)-strategies, value-authorities, and hope (goal)-designs.

2. The configuration was operated by the mechanism: ideal form of professional self-abstracted from the domain and social comparisons.

Acknowledgments. This work was supported by the Ministry of Science and Technology, Taiwan (MOST 102-2511-S-004-004; MOST 104-2410-H-004-143-MY2).

\section{References}

1. Adler, A. (1989). Character and talent (W. B. Wolfe, Trans.). Individual Psychology, 45, 515-526. (Original work published 1927)

2. Adler, A. (2009). Etiology and therapy of neuroses (T. Paulin \& N. D. Kapusta, Trans.). Journal of Individual Psychology, 65, 103-109. (Original work published 1930)

3. Ametller, J., \& Ryder, J. (2015). The impact of science curriculum content on students' subject choices in postcompulsory schooling. In E. K. Henriksen, J. Dillon, \& J. Ryder (Eds.), Understanding student participation and choice in science and technology education (pp. 103-118). Dordrecht, The Netherlands: Springer.

4. Ainley, M., \& Ainley, J. (2011). Student engagement with science in early adolescence: The contribution of enjoyment to students' continuing interest in learning about science. Contemporary Educational Psychology, 36, $4-12$.

5. Archer, L., DeWitt, J., Osborne, J., Dillon, J., Willis, B., \& Wong, B. (2012). Science aspirations, capital, and family habitus: How families shape children's engagement and identification with science. American Educational Research Journal, 49, 881-908.

6. Attarian, P. J. (1978). Early recollections: Predictors of vocational choice. Journal of Individual Psychology, 34, $56-62$.

7. Bandura, A. (2004). Health promotion by social cognitive means. Health Education \& Behavior, 31, 143-164.

8. Baron, R. A., Franklin, R. J., \& Hmieleski, K. M. (2013). Why Entrepreneurs often experience low, not high, levels of stress: The joint effects of selection and psychological capital. Journal of Management, 42, 742-768.

9. Bøe, M. V., Henriksen, E. K., Lyons, T., \& Schreiner, C. (2011). Participation in science and technology: Young people's achievement-related choices in late-modern societies. Studies in Science Education, 47, 37-72.

10.Bourdieu, P. (1973). Cultural reproduction and social reproduction. In R. Brown (Ed.), Knowledge, education, and cultural change: Papers in the sociology of education (pp. 71-84). London, UK: Taylor \& Francis.

11.Cerinsek, G., Hribar, T., Glodez, N., \& Dolinsek, S. (2013). Which are my future career priorities and what influenced my choice of studying science, technology, engineering or mathematics? Some insights on educational choice - case of Slovenia. International Journal of Science Education, 35, 2999-3025.

12.Charmaz, K. (2000). Grounded theory: Objectivist and constructivist methods. In N. K. Denzin \& Y. S. Lincoln (Eds.), Handbook of qualitative research (2nd ed.) (pp. 509-535). Thousand Oaks, CA: Sage.

13.Chen, D. J., \& Lim, V. K. (2012). Strength in adversity: The influence of psychological capital on job search. Journal of Organizational Behavior, 33, 811-839.

14.Chen, Q. (2014). Using TIMSS 2007 data to build mathematics achievement model of fourth graders in Hong Kong and Singapore. International Journal of Science and Mathematics Education, 12, 1519-1545.

15.Chiu, M.-S. (2012). The internal/external frame of reference model, big-fish-little-pond effect, and combined model for mathematics and science. Journal of Educational Psychology, 104, 87-107.

16.Chiu, M.-S. (2016). The challenge of learning physics before mathematics: A case study of curriculum change in Taiwan. Research in Science Education, 46, 767-786.

17. Cleaves, A. (2005). The formation of science choices in secondary school. International Journal of Science Education, 27, 471-486. 
18.Corbin, J., \& Strauss, A. (2007). Basics of qualitative research: Techniques and procedures for developing grounded theory. Thousand Oaks, CA: Sage.

19.Demerouti, E., van Eeuwijk, E., Snelder, M., \& Wild, U. (2011). Assessing the effects of a "personal effectiveness" training on psychological capital, assertiveness and self-awareness using self-other agreement. Career Development International, 16, 60-81.

20.Gazley, J. L., Remich, R., Naffziger-Hirsch, M. E., Keller, J., Campbell, P. B., \& McGee, R. (2014). Beyond preparation: Identity, cultural capital, and readiness for graduate school in the biomedical sciences. Journal of Research in Science Teaching, 51, 1021-1048.

21.Holmegaard, H. T., Madsen, L. M., \& Ulriksen, L. (2014). To choose or not to choose science: Constructions of desirable identities among young people considering a STEM higher education programme. International Journal of Science Education, 36, 186-215.

22.Holmegaard, H. T., Ulriksen, L. M., \& Madsen, L. M. (2014). The process of choosing what to study: A longitudinal study of upper secondary students' identity work when choosing higher education. Scandinavian Journal of Educational Research, 58, 21-40.

23.Holmegaard, H. T., Ulriksen, L., \& Madsen, L. M. (2015). A narrative approach to understand students' identities and choices. In E. K. Henriksen, J. Dillon, \& J. Ryder (Eds.), Understanding student participation and choice in science and technology education (pp. 31-42). ). Dordrecht, The Netherlands: Springer.

24.Hsu, P. L., Roth, W. M., Marshall, A., \& Guenette, F. (2009). To be or not to be? Discursive resources for (dis)identifying with science-related careers. Journal of Research in Science Teaching, 46, 1114-1136.

25.Kahlke, R. (2014). Generic qualitative approaches: Pitfalls and benefits of methodological mixology. International Journal of Qualitative Methods, 13, 37-52.

26.Kvale, S. (2006). Dominance through interviews and dialogues. Qualitative Inquiry, 12, 480-500.

27.Kvale, S. (2008). Qualitative inquiry between scientistic evidentialism, ethical subjectivism and the free market. International Review of Qualitative Research, 1, 5-18.

28.Labov, W. (2006). Narrative pre-construction. Narrative Inquiry, 6, 37-45.

29.Leu, Y.-C. \& Chiu, M.-S. (2015). Creative behaviors in mathematics: Relationships with abilities, demographics, affects and gifted behaviors. Thinking Skills and Creativity, 16, 40-50.

30.Luthans, F., Avey, J. B., Avolio, B. J., Norman, S. M., \& Combs, G. M. (2006). Psychological capital development: Toward a micro-intervention. Journal of Organizational Behavior, 27, 387-393.

31.Maltese, A. V., \& Tai, R. H. (2010). Eyeballs in the fridge: Sources of early interest in science. International Journal of Science Education, 32, 669-685.

32.Marsh, H. W., \& Hau, K. T. (2004). Explaining paradoxical relations between academic self-concepts and achievements: Cross-cultural generalizability of the internal/external frame of reference predictions across 26 countries. Journal of Educational Psychology, 96, 56-67.

33.Marton, F. (1981). Phenomenography: Describing conceptions of the world around us. Instructional Science, 10 , 177-200.

34.Miles, M. B., \& Huberman, A. M. (1994). Qualitative data analysis: An expanded sourcebook (2nd ed.). Thousand Oaks, CA: Sage.

35.O'Keefe, P. A., Ben-Eliyahu, A., \& Linnenbrink-Garcia, L. (2013). Shaping achievement goal orientations in a mastery-structured environment and concomitant changes in related contingencies of self-worth. Motivation and Emotion, 37, 50-64.

36.Packard, B. W. L., Babineau, M. E., \& Machado, H. (2012). Becoming job-ready collaborative future plans of Latina adolescent girls and their mothers in a low-income urban community. Journal of Adolescent Research, 27, 110-131.

37.Paik, S., \& Shim, W. J. (2013). Tracking and college major choices in academic high schools in South Korea. Asia-Pacific Education Researcher, 22, 389-397.

38.Pintrich, P. R. (2003). A motivational science perspective on the role of student motivation in learning and teaching contexts. Journal of Educational Psychology, 95, 667-686.

39.Regan, E., \& DeWitt, J. (2015). Attitudes, interest and factors influencing STEM enrolment behavior: An overview of relevant literature. In E. K. Henriksen, J. Dillon, \& J. Ryder (Eds.), Understanding student participation and choice in science and technology education (pp. 63-88). Dordrecht, The Netherlands: Springer. 
40.Ryan, R. M., \& Deci, E. L. (2000). Self-determination theory and the facilitation of intrinsic motivation, social development and well-being. American Psychologist, 55, 68-78.

41.Simpkins, S. D., Davis-Kean, P. E., \& Eccles, J. S. (2006). Math and science motivation: A longitudinal examination of the links between choices and beliefs. Developmental Psychology, 42, 70-83.

42.Siu, O. L., Bakker, A. B., \& Jiang, X. (2014). Psychological capital among university students: Relationships with study engagement and intrinsic motivation. Journal of Happiness Studies, 15, 979-994.

43.Strauss, A., \& Corbin, J. (1990). Basics of qualitative research: Grounded theory procedures and techniques. Newbury Park, CA: Sage.

44.Uitto, A. (2014). Interest, attitudes and self-efficacy beliefs explaining upper-secondary school students' orientation towards biology-related careers. International Journal of Science and Mathematics Education, 12 , 1425-1444.

45.Van Houtte, M., Vanderwegen, P., \& Vermeersch, H. H. (2014). 'Now I want to do something interesting, something fun'. A mixed-methods study into the determinants of horizontal gender segregation at a Belgian university. AISHE-J: All Ireland Journal of Teaching and Learning in Higher Education, 6(3), 1-20.

46.Venville, G., Rennie, L., Hanbury, C., \& Longnecker, N. (2013). Scientists reflect on why they chose to study science. Research in Science Education, 43, 2207-2233.

47.Wigfield, A., \& Eccles, J. S. (2000). Expectancy-value theory of achievement motivation. Contemporary Educational Psychology, 25, 68-81. 